\title{
Study on the Penetration of Video Teaching in College Physical Education Teaching
}

\author{
Li Sun \\ University of Electronic Science and Technology of China, Chengdu Sichuan, 610000, China
}

Keywords: Video teaching, College, Physical teaching, Penetration, Application

\begin{abstract}
The college physical education, in addition to improve students' physical fitness and all aspects of physical function, furthermore it can allow students to experience the charm and essence of the sport in physical education. College physical education has a strong dynamic characteristics, their teaching process also there is a corresponding difficulty, but not long-term importance to universities and teachers. This paper will analyze video teaching, teaching methods and explore television penetration in College Physical Education Teaching on this basis.
\end{abstract}

\section{Introduction}

College Physical Education is a comprehensive strong teaching subject, in addition to having a strong dynamic and practical outside sports theory teaching is also an important component. However, many PE teachers in the teaching process cannot grasp the important relationship between theory and practical teaching of Physical Education cannot be abstract content better show up, resulting in students learning in physical education cannot understand the sports action, sports teaching connotations. Therefore, the film and television teaching and college physical education combined, have important practical significance.

\section{Problems that college physical teaching faces}

\section{Lack of importance}

In all the problems faced by college physical education, and not enough emphasis is one of the most common problems. In university teaching, physical education has always received little attention, mostly teachers and students to focus on the main subjects of teaching and learning, for sports teaching is not given enough attention. This has led to most of the college students do not want to participate in sports teaching in the past, even though participation in sport to physical education, do not put all the energy, resulting in all aspects of college sports teaching runs sluggish, difficult to guarantee the quality of teaching.

\section{Focus on theory other than practices}

In college sports teaching, teachers need to show students different sports action, especially martial arts, kickboxing, sprinting and other teaching content requires students to master the appropriate technology movement. However, many teachers in the show when the action is not comprehensive, detailed and action details of the show is not in place, students are unable to grasp the basic essentials of the action, to specific learning adversely affected.

\section{Show no specific action}

In college sports teaching, teachers need to show students different sports action, especially martial arts, kickboxing, sprinting and other teaching content requires students to master the appropriate technology movement. However, many teachers in the show when the action is not comprehensive, detailed and action details of the show is not in place, students are unable to grasp the basic essentials of the action, to specific learning adversely affected. 


\section{Application advantage of video teaching}

Video teaching mainly teachers to use multimedia technology and network technology, in the classroom allow students to watch and teaching content related to the movie, video, video courseware, etc., with a strong intuition, and its specific application advantages as follows:

\section{Motivate students' interest}

Many college physical education teachers in teaching still follow the traditional teaching methods, the first physical education teaching basic theoretical knowledge to inform students, and then led the students to carry out practical activities. Such sports teaching methods not only there is a strong lag and dry nature, it cannot stimulate students' interest in learning. The video college physical education teaching and combine not only allows students to master the sport more intuitive theoretical knowledge, but also can take advantage of video materials attract the attention of students, the students will not feel the same college physical education boring as ever, boring. On this basis, students are more willing to participate in sport learn to go their own interest in sports will get the maximum excitation, and lay a solid foundation for college physical education.

\section{Demonstrate sportsmanship}

College physical education requires students to master the teaching contained sportsmanship, however, many teachers rely solely on the text to explain to demonstrate the spirit of sport, there is a big difficulty to accept those students, and teachers cannot achieve the desired teaching purposes. The video college physical education teaching and combined not only allow students in college sports watch related video content, which contains the emotional experience, but also understand the spirit of sportsmanship which contains this basis, and related sporting spirit inheritance and development to achieve deepening the development of university sports teaching.

\section{Inspire students thinking}

In the traditional sports teaching in the university, teachers paid little attention to whether or not to inspire students' thinking, leading to the development of students cannot achieve inspiring personal thinking in physical education. Application of video teaching in college physical education, students can feel a lot compared with the traditional teaching of the difference. Student while watching sports-related teaching video materials, can enrich their horizons, so that their imagination get the maximum play, but also to get a greater degree of personal enlightenment thinking, thinking individuals become more active.

In addition, video approach advantage in college physical education also includes the improvement of teaching efficiency, promote the development of teaching deepen, ensure teaching quality, the author not to repeat them here.

\section{Video teaching's penetration application in college physical teaching}

\section{Attract students' attention}

I have already mentioned above, one of the advantages of video teaching method is applied to stimulate students 'interest in learning, therefore, in college physical education, pedagogy video penetration application first is reflected in attracting students' attention to this aspect. Teachers through the application of video teaching method, you can use the information in the form of video, audio, images, etc. to attract and controlling the student's personal attention. In this way, students will focus on video materials, we can focus on sports teaching content more reasonable certainty, we can fully understand some of life do not often come into contact with sports action, as in the high jump the more important action back bend and stretch movements, Hurdle Steeplechase kick in the action and the like. Students learn about these actions in the first time, will feel difficult, and under the influence of psychological fear of difficulty are very easy to lose interest in sports learning. However, teachers in teaching if the positive application of video teaching, it can attract the attention of students through 
video materials to help students overcome the fear of difficulties, to help students learn to go into sports.

\section{Enlarge details}

In College physical education, many projects have included a series of details of the action, students are only master these details of the action, in order to truly master the skills of sports, for their learning and mastering sport has important practical significance. However, the details of the action sports, generally faster, can be said to be fleeting, students often fail to grasp the basic essentials and skills details of the operation. However, after the application of Video pedagogy teacher, you can be sport details of the action for effective amplification, so that students can quickly grasp the details of the action sports.

A sports college teachers in gymnastics class, when students on the body prance content, since this part has a series of details of the action, so that the teachers will be teaching television teaching method combined with body prance, to enable students to better grasp prancing body movement and inherent skills relevant details. The teacher asks students to watch the action in the learning process of professional gymnasts prance be video data when the body, and will carry out a full range of standard action athletes, to show three-dimensional, such as athlete's torso bending action, the degree of bending, prance when the action and the like. Students in professional athletes for video data, it can be analyzed from different angles and acquire the relevant skills more than physical prancing, prancing for the relevant physical skills also have a reasonable understanding and grasp. The teacher found that after students learn relevant skills pedagogy video prance body, not only mastered all the details of the action, but also the follow-up exercises for students to lay a solid foundation, but also to ensure the specific quality of teaching.

\section{Show continuous motions}

In college physical teaching, many projects have continuity of action and there are more fast action, if teachers want students to master the inherent skill sport, you need to allow students to grasp these actions to be analyzed. However, in the actual teaching work, the continuous nature of this sport strong action is impossible using conventional teaching methods to show, thus resulting in many students cannot master the continuity of action in the specific learning. However, the teachers use Video teaching method, it is possible to better show the continuity of the operation.

A university PE teachers at the basic movements and skills to explain the discovery of the long jump, long jump, there are more continuity of action, the students in learning run-up, jumping and other continuous action which is difficult to grasp the know-how, especially in the run-up for the individual specific speed and when vacated, and so difficult to grasp how vacated, students cannot learn quickly lead to long jump. The teacher personally demonstrated many times, we found students still cannot grasp the importance of the continuity of the operation, the quality of teaching is difficult to be fully guaranteed, this will be teaching television teaching and Long combined. The teachers' use of advanced network technology and computer technology, the whole process and its main technical movements to simulate long jump reproduction and use editing technology will reproduce the whole process of making a video courseware. Thereafter, the long jump teaching teachers demonstrate the continuity of action for students skills, and allow students to watch television has produced good courseware, and the long jump in the continuity of the operation of a series of frame-by-frame slow to show, in Finally, the long jump action to complete the show, and for each one to explain the slow motion is nuanced. The teacher found that after the use of video teaching on the continuity of action for a slower display, student projects for the continuity of action long jump with a more intuitive, impressed, mastered every slow-motion, and mastered the related motion skill. It is because of the teachers use video teaching method to show the continuity of action in physical education, to make students grasp the relevant action was reasonable, mastered the skills and the inherent characteristics of the long jump, but also the quality of PE teaching has been effectively guaranteed. 


\section{Difficulties motion analysis}

In the sports project, details of the action of some movement has a certain degree of difficulty, students in the learning process will feel more difficult. In this case, if the Video teacher teaching and college physical education combined, it allows students to quickly grasp the difficulty of movement, for its sports-related master has an important role in promoting, but also to help teachers in the teaching of the difficulties of teaching effective breakthrough, thus ensuring the quality of teaching.

When a university PE teachers explain to students hurdles related skills, the students found one of the difficulties for the operation difficult to grasp. Student opinion, the hurdles kick with great difficulty, improper kick amplitude, time will be knocked inappropriate hurdle, very easy to make his injury, so the students for learning hurdles with a strong fear of difficulty . The teachers in the students' grasp of the psychological factors and personal feelings after Hurdle Teaching Methodology applied film. The teacher asks the students to watch Liu Xiang Hurdle Teaching, Roberts, Johnson and other famous hurdle action, and video data playback to kick in when the action on the screen to pause processing. In this case, the teacher let the students watch professional athletes focusing mainly skills kick regard, the main method, and with his leg swing movement compared to find out the corresponding gap. In this way, students easily mastered in a specific hurdle in leg swing techniques and related essentials, for the difficulties kick aspect may be reasonable certainty, we have received good results in the subsequent hurdle practice. The teachers will be teaching and Physical Education Television difficulty of combining teaching, not only allow students to watch the video materials to break through the difficult process of learning, but also to effectively ensure the quality of students learning in sport, to avoid students in learning difficulties when the action have a strong fear of hardship.

\section{Improve the quality of teachers}

In addition to the main application of the above, the film Pedagogy in College Physical Education Teaching, also contribute to the overall construction of teachers, improving their quality of teachers. Compared with traditional pedagogy Television sports teaching methods, with a strong nature, require teachers with higher quality can be use. In the traditional physical education, PE teachers affected by various factors, unable to grasp the difficulty action, action continuity, etc., to the quality of teaching, teaching effect brought serious negative impact. Teachers in the application of video teaching method can not only learn to find, create, analyze video data, but also to correct the deficiencies that exist in the past, the teaching process, broaden personal horizons teaching, develop teaching ideas for physical education teaching have a positive role in promoting. In addition, college sports teachers in the application of video teaching method, it is also possible to grasp the latest trends in sports education and achieve personal re-learning, teaching ability, improve their overall quality of another. Personal Qualities of College PE Teachers get if effectively improve application quality and video effects Physical Education Teaching naturally can be guaranteed.

\section{Conclusions}

Currently, the college physical education has been widely carried out though, but under the influence of various factors, college physical education still faces many difficulties, the quality of teaching and the overall effect is difficult to be guaranteed. Video pedagogy as a new teaching method, the application itself has a strong advantage; college sports teachers should recognize the intrinsic value of their own advantages and Video teaching methods, and combining it with the Physical Education. Video Teaching in College Physical Education Teaching, can stimulate students' interest in learning, but also on the details of the action sports teaching and difficult operation, etc. a good show, with a strong value. 


\section{References}

[1] Wu Chunhong. On College public physical education introduce sports video teaching model. Modern Sports Science, 2014 (26).

[2] Jin Hui, Yu Libin. Multimedia Teaching Method and Effect of Wushu Teaching in Universities.Fighting (Sports forum),2010 (01) .

[3] Gong Yibo. Study on college physical teaching multiplex teaching model. Journal of Jilin normal university (Natural science edition),2010 (02) .

[4] Zhang Cixia, Sha Mian, Wu Yifeng. Current situation and analysis of college physical education multimedia teaching.Journal of Shangrao Normal College, 2010 (06) .

[5] Zhang Yonglong. Discussion on College public physical education introduce sports video teaching model. Journal of Shangqiu Normal College, 2013 (03) . 